\title{
BAR CODE STANDARDIZATION BY CREATING NEW SYMBOLOGY
}

\author{
Filip Cvitić, Mario-Osvin Pavčević, Jesenka Pibernik
}

Original scientific paper

This paper proposes a new symbology which eases the use of any two-dimensional matrix bar code on the market from a user perspective, respecting the rules of each 2D matrix bar code. By proposing a new symbology, the exisiting function patterns are transfered into a digital space and additional parts are added. By adding a part called the rim, any 2D matrix bar code can have the same function patterns and can be recognizable to the user, which enables the bar code standardization. For each 2D matrix bar code the rim can be precisely calculated. It can also carry two different 2D bar codes by implementing masks which can rearrange bits to form the desired graphic pattern. This research will contribute overall 2D matrix bar code standardization which will enable users to identify 2D matrix bar codes in the same way as other 2D matrix bar code symbologies. With this method a more user friendly bar code can be achieved.

Keywords: 2D code; bar code standardization; error correction; QR code; smart phone camera; symbology

\section{Standardizacija bar kodova sa stvaranjem nove tipizacije bar koda}

Izvorni znanstveni članak Ovaj članak predlaže novu tipizaciju bar koda koja pojednostavljuje korištenje bilo kojeg dvodimenzionalnog matričnog bar koda na tržištu iz perspektive korisnika, istovremeno poštujući pravila svakog od njih. Predlaganjem nove tipizacije postojeći funkcijski uzorci su prebačeni u digitalni prostor i dodatni su dijelovi ugrađeni. Dodavanjem dijela koji se zove obrub (the rim), bilo koji 2D matrični bar kod može imati iste funkcijske uzorke i biti prepoznatljiv korisniku, što omogućuje standardizaciju bar koda. Prateći korake u ovom članku, za svaki 2D matrični bar kod, obrub se može precizno izračunati. Nova tipizacija također može imati dva različita bar koda u isto vrijeme implementiranjem maski koje mogu transformirati bitove kako bi se formirao željeni grafiči uzorak. Ovim se istraživanjem pridonosi cijelokupnoj standardizaciji 2D matričnih bar kodova što će omogućiti korisnicima identificiranje bilo kojeg tipa 2D matričnog bar koda na isti način kao i druge 2D matrične bar kod tipizacije. Ovom metodom moguće je stvoriti jednostavnije bar kodove za korisnika.

\section{Keywords: 2D bar kod; ispravljanje pogrešaka; kamera pametnog telefona; QR kod; standardizacija bar koda; tipizacija}

\section{Introduction}

Every bar code requires its own group of algorithms and instructions in order for the smart phone to decode it $[1,2]$. Because of different 2D bar code symbologies there is not a universal standardization for them and for bar code readers [3]. This fact together with the lack of education about this technology among users is the main drawback of 2D bar codes. Beside that not all mobile phones come with preinstalled bar code readers [4]. The reliability violation issues of different bar codes stem from the fact that there are a lot of mobile bar code readers which do not have all the features for their seamless decoding (2D code mirroring, inverted color modules and similar [5]) and that they are not of the same quality. The lack of standardization represents a problem for the user that can cause a decrease in interest [6]. By investing in standardization and its further development every mobile application could read a 2D bar code in the future. That would consequently lead the user to master one bar code instead of four, five or more.

\section{Problem statement}

In order to encourage the user to scan bar codes in the purpose of participating in different campaigns, it is necessary to enable him an easier use.There are a lot of mobile bar code readers, but they are not able to scan every $2 \mathrm{D}$ bar code on the market. And because there are over 400 bar codes today [7] it is not easy for the user to visually know which type of bar code it is. Because of that it is necessary to simplify this kind of system (from a users' perspective) which would contribute to the standardization of this technology.

\section{Related work}

In order to create a new standardization method one has to take into account the technical restrictions of a $2 \mathrm{D}$ matrix bar code. Restrictions will be shown on the exampe of a QR code as the most popular 2D bar code. One has to take into account that QR codes are partially resistant to noise [8], distortion of perspective [9], inconsistent lightning conditions or partial covering of a part of the code. The distance between the bar code reader and the bar code surface, lack of smoothness of the surface and underexposure can also influence readability [10]. After a successful scan of a QR code, its image needs to be corrected before decoding the bit streams. The methods for doing that rely upon image denoising [11] or on camera shaking $[12,13]$. But based on the number of different decoding algorithms to read QR codes $[14,12]$ $[15 \div 20]$, it is noticeable that no single standardization method of reading a QR code exists. Also not all 2D bar codes are supported by GS1 [21] which means that there is space for improvement regarding this topic. Considering that, ideally, only the pixels in the center of the QR code are relevant for correct decoding [22], modules can be shrunk 3 times in a QR code and still remain readable as proved by H.-K. Chu et al. [23].

It is further possible to embed an image without using QR codes' Reed Solomon codes for correcting errors with a method called image blending [24]. In order to facilitate reading of a QR code with an embedded picture, the brightness and color of modules in such a method are changed. By using this knowledge a method has been developed which reshapes the regular squares of the embeded image inside the QR code using a novelty global transformation technique [25]. The method deforms a mesh to minimize the error of the QR code but at the 
same time preserves the important features of the embedded image. As encoded information does not always take a maximum number of characters per mode, there is a vacant area which is filled with redundant and pad codewords. This fact is used for creating methods

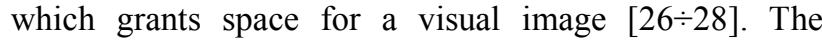
restriction of these methods comes from the fact that the size of the implemented image depends on the length of the codeword and their number [28]. Besides that, the user is limited by the surface on which he can place an image. In all mentioned methods althought they embellish QR codes and attract consumers attention, user still needs additional knowledge to know the difference between a QR code and other 2D matrix bar codes and differentiate them.

\section{Hypothesis}

It is possible to create a unique structure for $2 \mathrm{D}$ matrix bar codes for the purpose of facilitating their use for the user.

\section{Defining a new solution for bar codes standardization}

Each two-dimensional bar code has its own rules, its function patterns and its own information composition. In this paper a visual transformation of 2D matrix bar codes is presented which looks recognizable to the user. The idea of this symbology is based on bits rearrangement. Due to the fact that it is not possible to change individual rules for each 2D matrix bar code, it is necessary to add new elements and new function patterns in the new space for easier use of different 2D matrix bar codes. The name (Masked Matrix) MM code is taken for the new structure. The two left corners of the finder pattern are shaped the same, and the other two differently (idea taken from QR codes) as seen in Fig. 1. By grounding these finder pattern shapes, it is easy to find the right orientation of a bar code. In ISO/IEC 18004 [5] it is pointed out that the shapes of these patterns must not be repeated in the coding region, which is why this rule was taken into special consideration. The central square, where the $2 \mathrm{D}$ matrix bar code is embedded, is called the inner matrix. The content embedded in the inner matrix is called the message. Bits required for designing this message are placed around it. Therefore, this part of the MM code is called the rim (see Fig. 1).

The rim is divided into two parts; the outer rim and the inner rim (see Fig. 1). The outer rim consists of square modules which, depending on the number of bits which need to be placed, can be divided into four right-angled triangles at the most. The inner rim consists of triangles of the same shape. With the introduction of a triangle module the message in the inner matrix has been visibly enhanced. By using triangles (of four time smaller area than the square) more bits are placed in less space than what would be done using squares (see Fig. 1). Modules of both the outer and inner rim are grouped into four elements. By placing these elements around 2D matrix bar codes they could look the same and simultaneously encode different messages. Elements I, II and III lie below, left and above the inner matrix spread over its whole length. Unlike the first three elements, element $I V$ leans on and is equally rotated as element III (see Fig. 1).

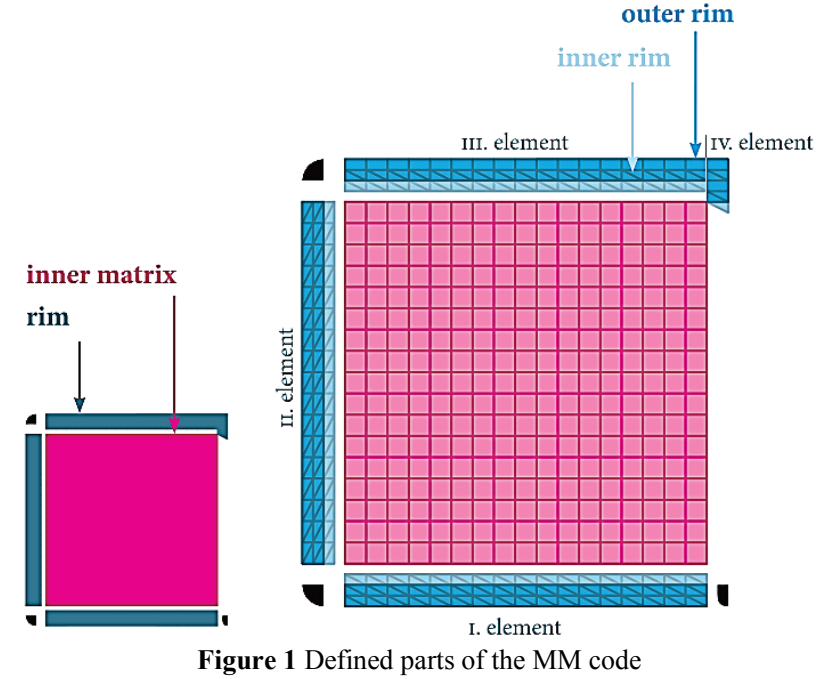

In the $M M$ code the rim takes on the role of the timing pattern as well. That pattern is omitted because there are only two combinations where all the bits in the rim have value 0 (light) or 1 (dark). For example, in the MM code for encoding the smallest version of Micro $\mathrm{QR}$ code M1 which has 121 modules, the rim consists of 148 modules, which makes a total of $2^{148}$ combinations. This means that out of $2^{148}$ combinations, there are two cases in which all the bits are equally bright ( 0 or 1$)$. The same fact can be concluded for every dimension of the message. All the function patterns, including elements I, II, III and IV, are placed in one layer of the rim. When the space of one layer is not sufficient for placing all the information, a new layer is added (see Fig. 3).

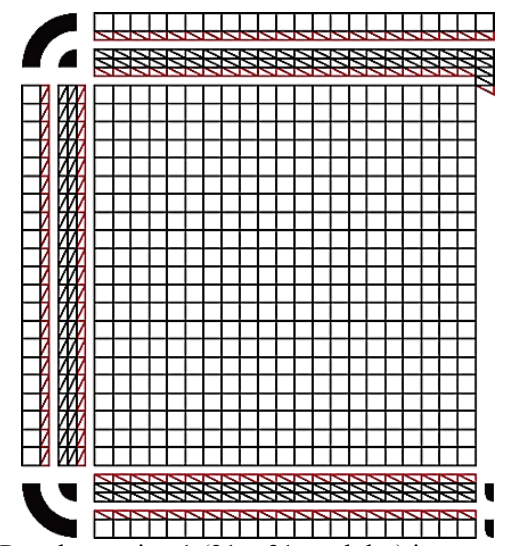

Figure 2 QR code, version $1(21 \times 21$ modules $)$ in a new symbology. Number of modules in a QR code V1: 441 (with function bits 466), number of rim modules: 579

By adding new layers, finder patterns are also modified. Finder patterns in the lower left and upper left corners receive a concentric element three times larger than the preceding one for each added layer. At the same time the lower right finder pattern is copied and nudged for a height of that same pattern (see Fig. 2).

In every layer, the elements in the outer rim are firstly filled in a clockwise direction, after which the inner rim is filled in the same direction. Depending on the $2 \mathrm{D}$ matrix bar code's dimension, the size of the inner matrix is modified as well. The first bit is placed in the lower left corner of the outer rim and the following as shown in Fig. 3. 


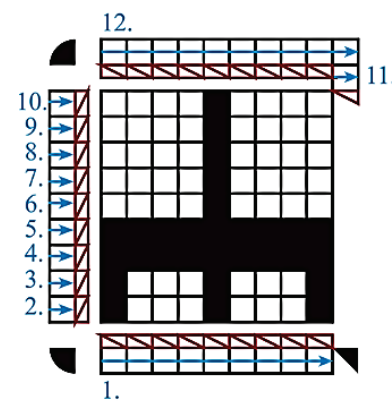

Figure 3 Sequence of filling bits in a QR code

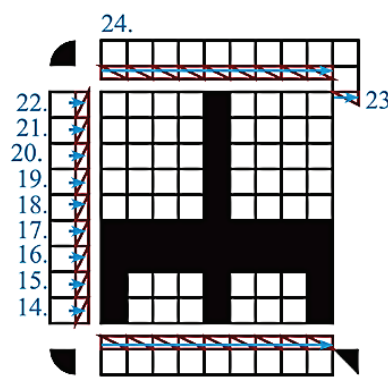

13.

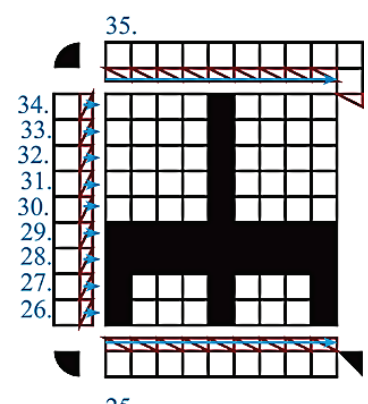

25

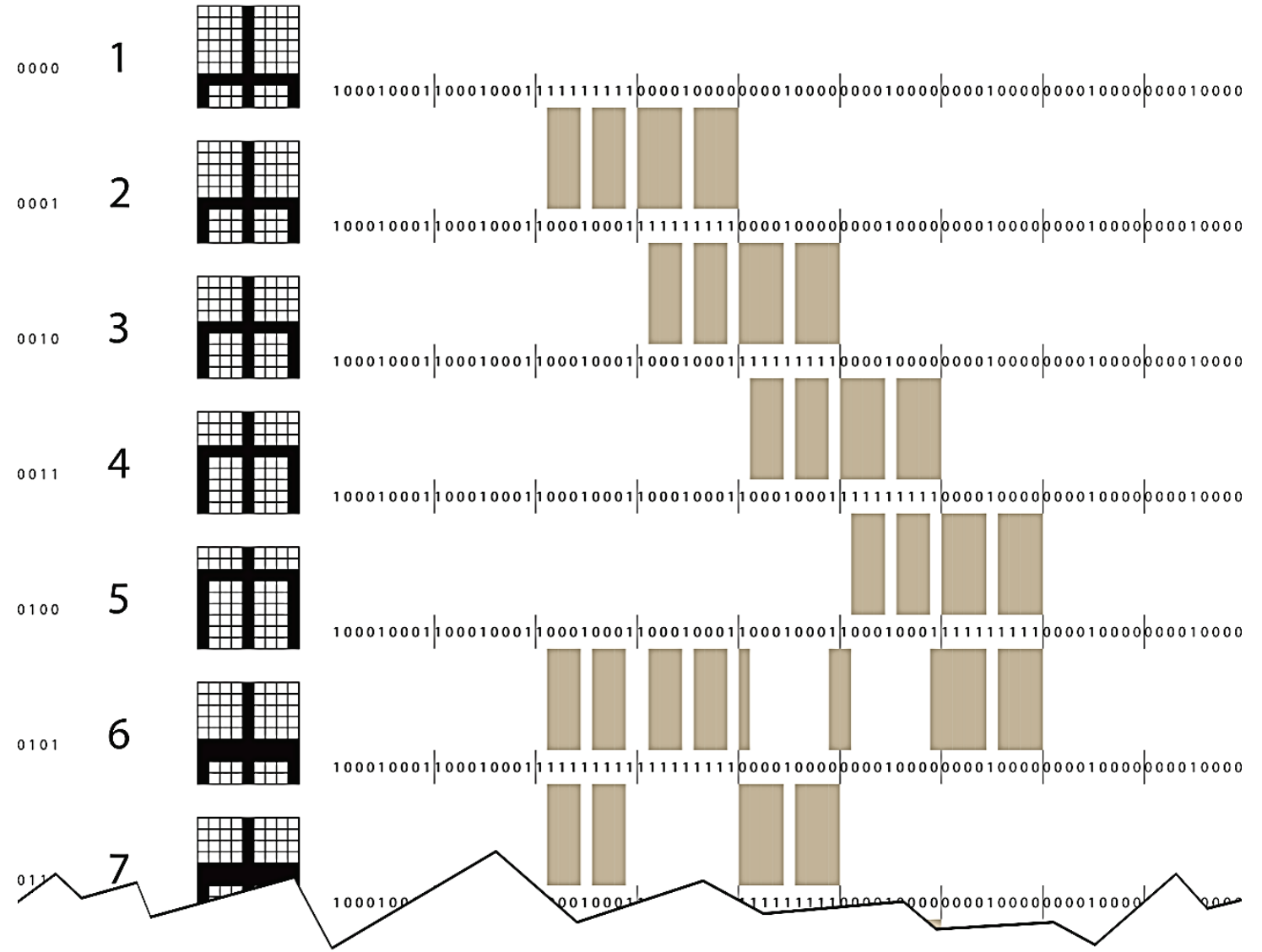

Figure 4 Mask folder showing the glagolitic letter A

\section{Filling the rim with the display matrix}

The rim is filled with the so-called display matrix, which transforms the message into a mask. The mask represents a method of overlaying certain information, while completely preserving the encoded message. In the MM code masks are also used for storing a certain part of the encoded message. The author of a mask has the freedom to design a pattern to his desire and does not need to worry whether the encoded message is going to be preserved by using a specific graphic pattern or not. In order to communicate different kinds of messages this principle allows the creation of a sufficiently large number of different masks. Because of that, any designed graphic pattern has to have a certain number of masks placed in the mask folder (set of masks). On one hand it is desirable to have masks graphically as similar as possible, and on the other hand to have different binary notation for every two masks which differ on as many positions as possible. Each mask differs from the previous one in a couple of positions. $n$ last bits of the message to be stored in the inner matrix determine the ordinal number of the mask from the mask folder (not greater than $2^{n}$ ) which will be chosen to represent the MM code. In an example where $n=4$, 16 masks were created (see Fig. 4). Unlike designed QR codes $[29 \div 32]$, masks that represent characters or images that one can recognize do not reduce their reliability. The main characteristic of masks in the mask folder is that they provide additional error correction. In addition to the error correction on the level of individual codewords, masks allow error correction on the level of the whole message.

After masks have been created and the display matrix placed in the rim it is neccesary to place function bits. Having done so, the coding procedure is completed and the final visual form of the MM code is created. A simplified process of creating the MM code is shown through the next algorithm (see Fig. 5). 


\section{I. phase}

\begin{tabular}{|c|c|}
\hline message & the inner matrix \\
\hline ENCODE THE MESSAGE - GENERATE A & DETERMINE THE DIMENSIONS OF THE \\
STRUCTURE'S INNER MATRIX ON THE \\
BASIS OF EMBEDDED 2D BAR CODE \\
$\downarrow$ \\
DETERMINE THE MASK \\
$\downarrow$ \\
DETERMINE THE DISPLAY MATRIX \\
\hline
\end{tabular}

\section{II. phase}

III. phase

\begin{tabular}{|c}
\hline the rim \\
\hline ON THE BASIS OF DISPLAY MATRIX \\
DETERMINE THE NUMBER OF RIM'S \\
MODULES
\end{tabular}
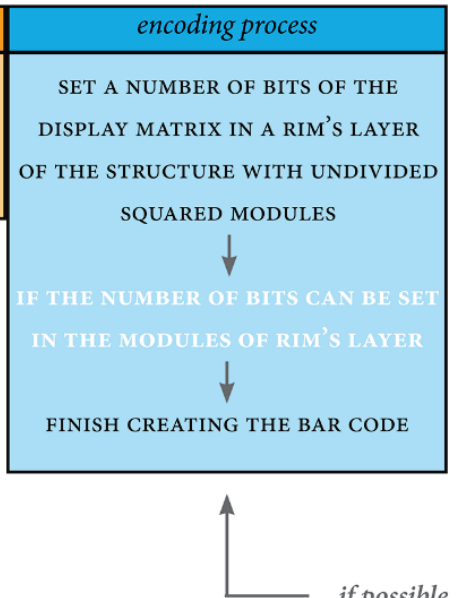

$\uparrow$

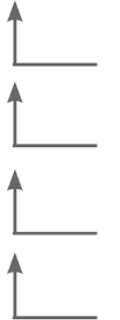

if possible

if possible

if possible

if possible

if possible
IV. phase

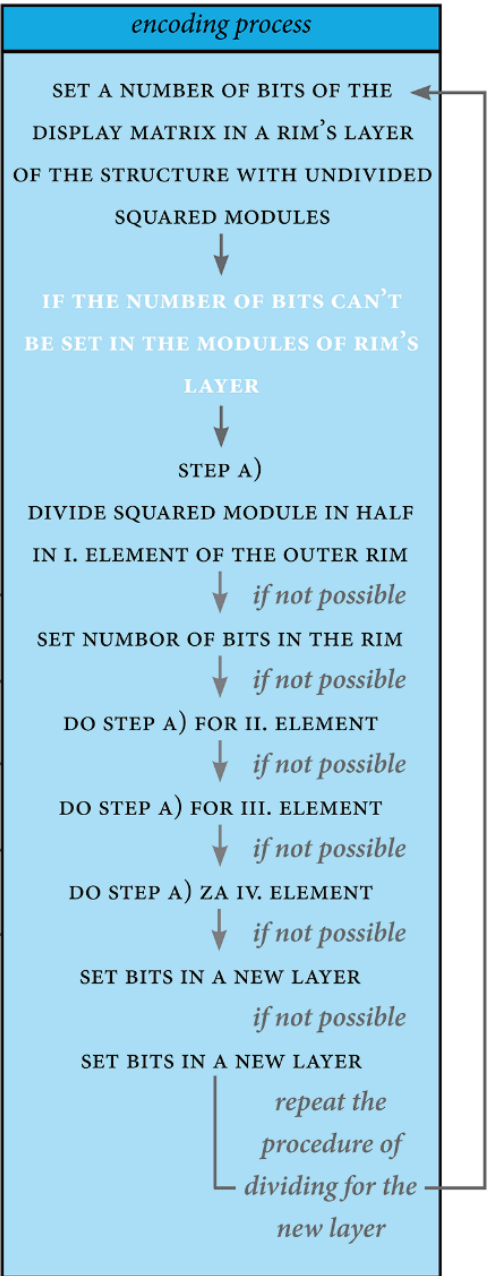

Figure 5 The algorithm of making a symbology with the division of modules in the outer rim

\section{Codes for function bits in the MM code}

Bar code's function bits contain important information for defining its basic parts like size, coordinates, alignment etc. In the MMcode, function bits enable the computer to know the divison of squared modules in the outer rim, in which layer and in which element are the modules divided and how many layers does a certain MM code have. Function bits are positioned in the rim after the display matrix. Considering that they are important for correctly scanned codes, it is important to add parity bits (bits for parity check) to enable the detection and correction of errors. Because of that three short codes are used: $[3,1,3],[4,2,2]$ and $[6$, $4,2]$. This information is written in the following way. From 27 function bits the first six bits from the linear code $[6,4,3]$ are reserved for the ordinal number of the layer in which all information about that layer are defined. Considering that the maximum version of the $\mathrm{QR}$ code is version 40 with $177 \times 177$ modules, it is sufficient to have 10 layers. Therefore six bits are chosen in order to define 16 layers in the structure of the MM code. Inner matrices with dimensions from $11 \times 11$ to $17 \times 17$ do not have these six bits because they contain only one layer. After these six bits 000 or 111 is set. If in one layer all elements are equally divided, then they are described 
simultaneously, and are written as 111 . If that is not the case, 000 is placed. After that the computer application counts to the next four elements. Each element is defined with four bits which determine into how many parts is the basic squared module divided. Single module division is marked with 0000 , with 0111 double division, with 1010 triple division and with 1101 quadruple division. Besides that, the computer needs to know which bar code is in the inner matrix in order to activate associated computer application (bar code reader) for decoding that bar code. So two last bits 00 or 11 from the code [2, 1, 2] are placed, which means that the programmer has the option to choose between two computer applications (for example iNigma [33] and Neo Reader [34]). As today's computer applications can decode a number of popular bar codes, now such a possibility will be available to the programmer. This code does not have redundancy bits for error correction, but it can detect errors. With this step 27 function bits are placed in the rim of the MM code with the inner matrix of dimensions from $21 \times 21$ upward. In the smallest QR code version M1 which has 148 modules, function bits are placed following previously described steps.On the QR code example V4 (see Fig. 2) there are 47 modules free for placing function bits. If the rest of the empty modules are not filled, bits with value 0 are added. The sole encoding of information and their recognition could not be possible without the previous detection of the new symbology. Finder patterns, which are reinvented for this symbology, have that purpose.

\section{Calculating the divison of modules in each layer}

In order to find the required number of modules in the rim, it is necessary to comply with the formula in the following steps. First of all it is important to know how many bits the 2D matrix bar code, embedded into the inner matrix, has. As the number of bits in the $2 \mathrm{D}$ matrix bar code stays the same as the number of modules of the inner matrix, that number is $n \times n$. The sign $n$ indicates the number of modules by width and modules by height of the inner matrix but that is not the entire number of bits necessary to place in the rim. To the $n^{2}$ number, in case a Micro QR code is placed in the inner matrix, 23 function bits are added. If a standard $\mathrm{QR}$ code is placed (from version $21 \times 21$ upward), 27 functional bits are added to the rim.

$$
n^{2}+23 \text { total number of bits for Micro QR code }
$$

or

$$
n^{2}+27 \text { total number of bits for standard QR code }
$$

The first number (1) is used if $n \leq 17$, and the other one (2) if $n>17$. The upper expressions (1) (2) are possible to be written in another way

$$
n^{2}+\alpha
$$

where $\alpha$ represents the number of function bits according to the specified condition above (1) (2). After the number of bits which need to be placed in the rim is known, it is necessary to find out in how many layers $s$ they need to be distributed. This is obtained through the following formula:

$s=\left\lceil\frac{n^{2}+\alpha-(18 n+9)}{18 n+6}\right\rceil$

The number $18 n+9$ represents the total possible number of bits in one layer. In the first layer the total number of bits in the outer rim is $12 n+8$ while the total number of bits in the inner rim is $6 n+1$. Therefore the total number of bits in the whole rim of the first layer is $12 n+8+6 n+$ $1=18 n+9$. The number $18 n+6$ represents the total number of bits in every other layer except the first one. If the number of required bits which need to be placed in the rim exceeds the number of modules in one layer, with the above formula (4), the number of layers $s$ required for bit placement is found. When the number of layers $s$ is known, it is necessary to find out how the squared modules in the layers are divided. If $s>1$, one important fact for all layers except for the most outer one is known. Those modules in all elements of the outer rim are divided fourfold $(x=4)$.

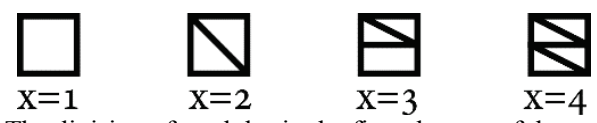

Figure 6 The division of modules in the first element of the outer rim

Because of that it is necessary to find just the division of the squared modules in that last layer. In order to get to that information the remaining number of bits for the last layer needs to be calculated:

$D=\left\{\begin{array}{c}n^{2}+\alpha, s=1 \\ n^{2}+\alpha-(18 n+9)-(18 n+6) \times(s-2), s \geq 2\end{array}\right.$

After the variable $D$ is known, two more variables have to be determined. Variable $p_{x}$ which shows to which maximum division some of the 4 elements are divided and variable $p_{e l}$ which determines to which element is the division $p_{x}$ applied. As the maximum division of the module is $x=4, p_{x}$ can acquire only the following values:

$p_{x} \in\{1,2,3,4\}$

From the following conditions:

$D \leq 9 n+3 \rightarrow x=1$
$9 n+4 \leq D \leq 12 n+4 \rightarrow x=2$
$12 n+5 \leq D \leq 15 n+5 \rightarrow x=3$
$15 n+6 \leq D \leq 18 n+6 \rightarrow x=4$

variable $p_{x}$ is calculated according to the following formula:

$p_{x}=\left\lceil\frac{D}{3 n+1}\right\rceil-2$

Variable $p_{e l}$ can also have only the values $p_{e l} \in\{1,2,3,4\}$ considering that the MM code has only 4 elements. So for calculating the variable $p_{e l}$, one has to apply the following formula:

$p_{e l}=\left\lceil\frac{D}{n\left(p_{x}+2\right)}\right\rceil$ 


\section{The possibilities of the MM code}

By introducing new elements and creating a new symbology, design of 2D matrix bar code's whole surface is enabled. In this way, with a mask, bit strings are rearranged to make a desired graphic pattern. By using masks it is possible to describe MM code as a new symbology which has a 2D matrix bar code embedded inside its structure. The semantic message (the graphic pattern) is therefore readable by the user and the encoded message by the bar code reader. The final messages could still be generated with one of existing 2D matrix bar codes found on the market. Therefore it is not necessary to create a new mobile application that will read the message encoded in a QR code, Aztec code, Data Matrix or similar. But in order to come to those $2 \mathrm{D}$ matrix bar codes embedded in the MM code, it is necessary to create a mobile application that will read the new symbology (see Fig. 7).

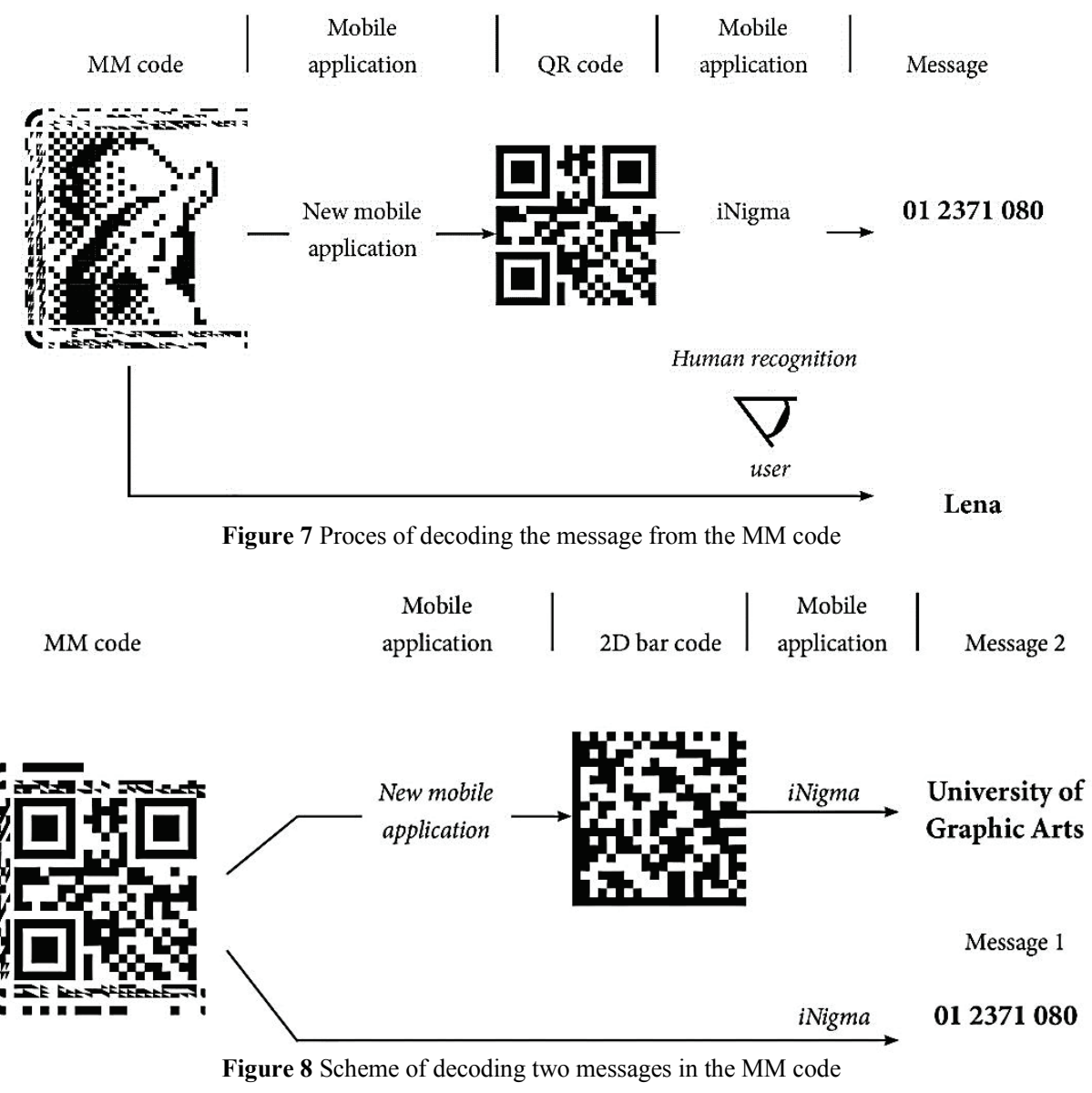

With this method, masks can be designed as one of the existing bar codes, which makes the MM code the carrier of two different messages no matter which 2D matrix bar code is embedded in the new symbology (see Fig. 8).
Because the mask shows one of the existing 2D matrix bar codes, the mask can be used for displaying different encoded messages in the MM code. The principle of storing $n$ last bits of the inner matrix is somewhat different from the described section 5 above. This is a subject of future research.
Message 1

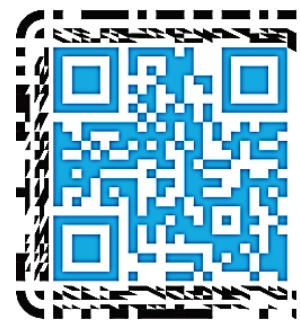

Message 2

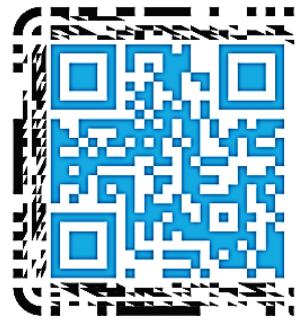

Message 3

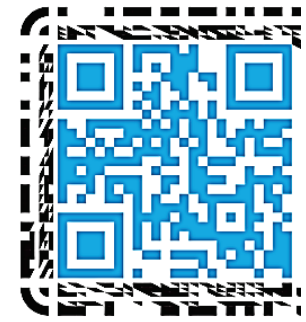

The same QR code

Figure 9 Placing the same QR code on three different codes by using masks 


\section{Minimal pixel size investigation}

By having a new triangle module it was also important to investigate the smallest size that they can have. So the research was conducted to determine the minimum size of a module at which QR codes can still be read by most cell phones [35]. That size will then be taken for triangle modules used in the MM code. The research was conducted on the following phones: iPhone $3 \mathrm{G}$, iPhone 3GS, Sony Ericsson Xperia Arc, Nokia N97, Sony Ericsson Xperia X10 mini, Sony Ericsson E10i and Samsung GT 15500. The research analyzed a total of 6 QR codes in different sizes, generated on the following website: http://keremerkan.net/qr-code-and-2d-codegenerator/. The same message was incorporated in all the QR codes and they all had the same level of error correction - the Q level (25\% of errors can be corrected). The results of this research can be seen in the table (Tab. 1). The research was conducted on 7 different mobile devices at two different temperatures of light $(5000 \mathrm{~K}$ and $7500 \mathrm{~K}$ ) at a distance of $6 \mathrm{~cm}$ to $50 \mathrm{~cm}$ between the camera of the phone and the QR code image on paper. Each cell phone was used 3 times to try to decode each QR code. All of the above-mentioned phones reliably read $\mathrm{QR}$ codes from smaller and greater distances if they are $20 \times 20 \mathrm{~mm}$ in size (see Tab. 1).

\begin{tabular}{|c|c|c|c|c|c|c|c|c|c|c|c|c|c|c|}
\hline \multirow{3}{*}{$\begin{array}{l}\text { QR code } \\
\text { size } \\
30 \mathrm{~mm}\end{array}$} & \multirow{2}{*}{\multicolumn{2}{|c|}{$\begin{array}{l}\text { iPhone } 3 G \\
5000 \mathrm{~K} \mid 7500 \mathrm{~K}\end{array}$}} & \multicolumn{2}{|c|}{ iPhone 3GS } & \multicolumn{2}{|c|}{\begin{tabular}{|c|} 
Sony Ericsson \\
Xperia Arc
\end{tabular}} & \multicolumn{2}{|c|}{ Nokia N97 } & \multicolumn{2}{|c|}{$\begin{array}{l}\text { Sony Ericsson } \\
\text { Xperia X10 mini }\end{array}$} & \multicolumn{2}{|c|}{$\begin{array}{c}\text { Sony Ericsson } \\
\text { Xperia E10i }\end{array}$} & \multicolumn{2}{|c|}{$\begin{array}{l}\text { Samsung } \\
\text { GT } 15500\end{array}$} \\
\hline & & & $5000 \mathrm{~K}$ & $7500 \mathrm{~K}$ & $5000 \mathrm{~K}$ & $7500 \mathrm{~K}$ & $5000 \mathrm{~K}$ & $7500 \mathrm{~K}$ & $5000 \mathrm{~K}$ & $7500 \mathrm{~K}$ & $5000 \mathrm{~K}$ & $7500 \mathrm{~K}$ & $5000 \mathrm{~K}$ & $7500 \mathrm{~K}$ \\
\hline & $6-40$ & $6-41$ & $6-48$ & $6-48$ & $7-50$ & $8-50$ & $11-50$ & $11-50$ & $6-50$ & $6-50$ & $6-50$ & $6-50$ & $5-29$ & $6-29$ \\
\hline $25 \mathrm{~mm}$ & $6-30$ & $6-35$ & $5-41$ & $6-41$ & $6-50$ & $7-50$ & $11-50$ & $11-50$ & $6-42$ & $6-42$ & $6-42$ & $6-42$ & $5-24$ & $5-24$ \\
\hline $20 \mathrm{~mm}$ & $7-24$ & $6-25$ & $5-33$ & $5-31$ & $6-50$ & $6-50$ & $10-45$ & $9-46$ & $6-34$ & $6-34$ & $6-34$ & $6-34$ & $4-20$ & $4-19$ \\
\hline $15 \mathrm{~mm}$ & I & I & $5-32$ & 4-24 & $7-40$ & $7-40$ & $7-32$ & $7-32$ & $6-26$ & $6-26$ & $6-26$ & $6-26$ & $5-11$ & $5-12$ \\
\hline $10 \mathrm{~mm}$ & I & I & $5-11$ & $6-15$ & $10-26$ & $10-26$ & I & 1 & $6-11$ & 6-15 & $6-11$ & $6-15$ & 1 & I \\
\hline $5 \mathrm{~mm}$ & I & 1 & 1 & 1 & 1 & 1 & 1 & 1 & I & I & I & 1 & I & I \\
\hline
\end{tabular}

From the QR code size $20 \times 20 \mathrm{~mm}$ version 3 , its basic module was used as the minimum size.That means that the minimum size of the QR code module for correct reading is $0,7 \times 0,7 \mathrm{~mm}$ if it is a square and $0,7 \times 0,35$ $\mathrm{mm}$ if the module is a triangle. The minimal size of the module in this research is used as the basic size upon which the modules of a MM code are built - both for squares and triangles. Based on the scaned QR codes it is expected that a bar code reader would be able to read MM code.

\section{Limitations and research}

It is necessary to increase the safety for the encoding and decoding procedure through further research. For sizes defined in ISO/IEC 18004, 2006 two linear codes shall be used; [28, 8, 11] for the rim and [25, 8, 9] for the inner matrix. In order for the masks of the same object to remain recognizable and understandable to the user, the minimal distance between them will be determined using Weber's law [36]. In order to explore the limitations on the print medium it is necessary to create a mobile application specificaly for the MM code. Having that tool, parameters of reproduction tehniques can then be researched (resolution of the printed MM code, the efficency of the finder pattern, incorporation of different grey tone values in the MM code, false readings).

Mentioned innovations have made improvements of designed QR codes and have made effort to create visually pleasing $2 \mathrm{D}$ bar codes but at the same time have kept its readability with the bar code reader. But they do not change the recognizability of the QR code for the user. It is necessary to research the applicability of these innovations for Data Matrix, Aztec code and use them as improvements for all 2D matrix bar codes. In that way these innovations could contribute to overall standardization of 2D matrix bar codes.

\section{Conclusion}

In this paper it has been proven that it is possible to equalize function patterns from 2D matrix bar codes by having a display matrix placed in the rim. By adding new parts, described in the paper, it is possible to contribute to the overall standardization of 2D matrix bar codes. It has also been shown that the minimal size for placing a triangle module into a $2 \mathrm{D}$ matrix bar code is $0,7 \mathrm{~mm}$ in its longest side necessary for creating the rim. Because of this method, the user will be educated to identify a $2 \mathrm{D}$ matrix bar code without the need to memorise two, three or more of them. It will contribute to a better connection between users and bar codes and achieve a new level of visual and cognitive communication between them. With bar codes designed in such a way, messages can be created in a more meaningful and creative way than so far, which can also lead to a more frequent use of bar codes.

\section{Acknowledgements}

This work has been supported in part by Croatian Science Foundation under the project 1637.

\section{References}

[1] Kavčić U.; Muck T.; Lozo B., Žitnik A. Multi-color 2D Datamatrix codes with poorly readable colors. // Journal of Graphic Engineering and Design. 1, 1(2010), pp. 1-13

[2] Evers, P. Moseycode, a new chapter in mobile barcoding. The next Web. 2008. http://thenextweb.com/2008/01/05/ 
moseycode-a-new-chapter-in-mobile-barcoding/\#!yiRm3 (8.7.2014).

[3] Klie, L. Who benefits from QR Codes? CRM magazine. Information Today Inc., Medford. 2012. pp. 11-12.

[4] Villàn, R.; Voloshynovskiy, S.; Koval, O.; Pun, T. Multilevel 2D Bar Codes: Towards High Capacity Storage Modules for Multimedia Security and Management. Security, Steganography, and Watermarking of Multimedia Contents '05/ San Jose, 2005, pp. 1-12.

[5] ISO/IEC 18004. Information technology - Automatic identification and data capture techniques - QR Code 2005 bar code symbology specification. ISO/IEC, Geneva. 2006.

[6] Williams, B. Understanding Barcoding. Pira international Ltd, Leatherhead. 2004.

[7] Joyce, J. R. Bar Codes 101, Introducing to Bar Codes. Scientific Computing. 2013. http://www.scientificcomputing.com/articles-DS-BarCodes-101-102011.aspx. (2.6.2014)

[8] Sun M.; Fang Z.; Fu L.; Zhao F., 2010. Identification of QR Codes Based on Pattern Recognition. World Automation Congress (WAC). http://ieeexplore.ieee.org/xpl/ mostRecentIssue.jsp?punumber=5626921 (28.4.2015).

[9] Chen, C.; Kot, A. C.; Yang, H. A two-stage quality measure for mobile phone captured 2D barcode images. // Pattern Recognition. 46, 9 (2013), pp. 2588-2598. DOl: 10.1016/j.patcog.2013.01.031

[10] Xu, G.; Li, R.; Yang, L.; Liu, X. Identification and Recovery of the Blurred QR Code Image. 2012 International Conference on Computer Science and Service System / Nanjing, China, 2012, pp. 2257-2260. DOl 10.1109/CSSS.2012.560

[11] Lin, C. C.; Chen, M. S. A general scheme for QR-code image denoising on the camera phone. M.S. thesis. Department of Electrical Engineering, National Taiwan University, 2009.

[12] Chu, C.-H.; Yang, D.-N.; Chen, M.-S. Image stablization for 2D barcode in handheld devices. MULTIMEDIA '07 Proceedings of the $15^{\text {th }}$ international conference on Multimedia / New York, New York, USA, 2007.

[13] Lin, J.-A.; Fuh, C.-S. 2D Barcode Image Decoding. // Mathematical Problems in Engineering. 2013, 3(2013), pp 1-10. DOI: $10.1155 / 2013 / 848276$

[14] Chang, Y. H.; Chu, C. H.; Chen, M. S. A general scheme for extracting QR code from a non-uniform background in camera phones and applications. M.S. thesis. Department of Electrical Engineering, National Taiwan University, 2007.

[15] Kato, Y.; Deguchi, D.; Takahashi, T.; Ide, I.; Murase, H. Low Resolution QR-Code Recognition by Applying SuperResolution Using the Property of QR-Codes. 2011 International Conference on Document Analysis and Recognition - ICDAR '11 / Beijing, China, 2011.

[16] Lai, C. Y.; Chen, M. S. Extracting QR Code from a nonuniform background image in embedded mobile phones. M.S. thesis. Department of Electrical Engineering, National Taiwan University, 2007

[17] Liu, Y.; Yang, J.; Liu, M. Recognition of QR Code with mobile phones. 2008 Chinese Control and Decision Conference CCDC 2008 / Yantai, Shandong, 2008, pp. 203-206. DOI: 10.1109/CCDC.2008.4597299

[18] Muñoz-mejías, D.; González-díaz, I.; Díaz-de-maría, F. A Low-Complexity Pre-Processing System for Restoring Low-Quality QR Code Images. // IEEE Transactions on Consumer Electronics. 57, 3(2011), pp. 1320-1328. DOI: 10.1109/TCE.2011.6018890

[19] Xiong, Z.; Cuiqun, H.; Guodong, L.; Zhijun, L. A binarization method of quick response code image. $20102^{\text {nd }}$ International Conference on Signal Processing Systems ICSPS/ Dalian, China, 2010.

[20] Zhou, J.; Liu, Y.; Li, P. Research on Binarization of QR Code Image. 2010 International Conference on Multimedia
Technology ICMT/ Ningbo, China, 2010. DOI: 10.1109/icmult.2010.5631155

[21] GS1. General Specifications, Version 15 (issue 2). United States, New Jersey. 2015.

[22] Garateguy, G. J.; Arce, G. R.; Lau, D. L.; Villarreal, O. P. QR Images: Optimized Image Embedding in QR Codes. // IEEE Transactions on Image Processing: A Publication of the IEEE Signal Processing Society. 23, 7(2014), pp. 28422853. DOI: $10.1109 /$ TIP.2014.2321501

[23] Chu, H.-K.; Chang, C.-S.; Lee, R.-R.; Niloy, M. J. Halftone QR Codes. // ACM Transactions on Graphics. 32, 6(2013), pp. 217:1-217:8

[24] Baharav, Z.; Kakarala, R. Visually significant QR codes: Image blending and statistical analysis. // 2013 IEEE International Conference on Multimedia and Expo (ICME)/ San Jose, California, 2013, pp. 1-6. DOI: 10.1109/ICME.2013.6607571

[25] Lin, Y.-S.; Luo, S.-J.; Chen, B.-Y. Artistic QR Code Embellishment. // Computer Graphics Forum. 32, 7 (2013), pp. 137-146. DOI: 10.1111/cgf.12221

[26] Wakahara, T.; Yamamoto, N. Image Processing of 2Dimensional Barcode. $/ / 14^{\text {th }}$ International Conference on Network-Based Information Systems / Tirana, Albania, 2011, pp. 484-490. DOI: 10.1109/nbis.2011.80

[27] Lin, Y.-H.; Chang, Y.-P.; Wu, J.-L. Appearance-Based QR Code Beautifier. // IEEE Transactions on Multimedia. 15, 8 (2013), pp. 2198-2207. DOI: 10.1109/TMM.2013.2271745

[28] Skawattananon, C.; Vongpradhip S. An improved method to embed larger image in QR code. The $201310^{\text {th }}$ International Joint Conference on Computer Science and Software Engineering (JCSSE)/ Maha Sarakham, Thailand, 2013, pp. 64-69. DOI: 10.1109/jcsse.2013.6567321

[29] Visualead, 2013. http://www.visualead.com/ (8.7.2014)

[30] QR Stuff, 2013. QRStuff QR Codes Go Visual. http://www.qrstuff.com/blog/ (8.7.2014.)

[31] Chu, H. K.; Chang, C. S.; Lee, R. R., Mitra, N. J. Halftone QR Codes. // ACM Transactions on Graphics. 32, 6(2013), pp. 217:1-217:8.

[32] Lin, Y. S.; Luo, S. J.; Chen, B.Y. Artistic QR Code Embellishment. // Computer Graphics Forum. 32, 7(2013), pp. 137-146. DOI: 10.1111/cgf.12221

[33] 3Gvision, 2013. i-nigma home page. http://www.inigma.com/i-nigmahp.html (28.4.2015).

[34] NeoMedia, 2015. NeoReaderhome page. http://www.neoreader.com/ (28.4.2015).

[36] Weber, E. H. Weber's Law of Just Noticeable Differences, USD Internet Sensation \& Perception Laboratory. 1834 http://apps.usd.edu/coglab/ WebersLaw.html (08.7.2014).

[35] Cvitić, F.; Pibernik, J. Decoding different patterns in various grey tones incorporated in the QR code. // Acta Graphica. 25, 1-2(2014), pp. 11-22.

\section{Authors' addresses}

\section{Filip Cvitić, mag. art.}

Jesenka Pibernik, prof. dr. sc.

Faculty of Graphic Arts, Department for Graphic Design and Image Processing

Getaldićeva 2, 10000 Zagreb, Croatia

E-mail: filipcvitic@gmail.com

E-mail: jpiberni@grf.hr

Mario Osvin Pavčević, prof. dr. sc.

University of Zagreb, Faculty of electrical engineering and computing, Department of applied mathematics Unska 3, 10000 Zagreb, Croatia

E-mail: mario.pavcevic@fer.hr 